\title{
REENCONTRAR 0 SENTIDO E O SABOR DOS SABERES ESCOLARES
}

\author{
Adriana Mohr* \\ Fernando Dias de Ávila Pires**
}

Entrevista com Jean-Pierre Astolfi (Professor titular emérito, CIVIIC Rouen'), Des repères pour enseigner autrement [Reflexões para ensinar de outro modo], 11 de setembro de 2009. Todos os direitos reservados, Educagri Éditions, 2010, 26 Bd

Petit-Jean BP 8799921079 Dijon, entrevista: Bernadette Fleury, imagens: Eric Billon, co-produção: AgroCampus Ouest.

Publicado em FLEURY, B. (coord.). Actes du Colloque Enseigner autrement, oui mais comment? Dijon: Educagri. 2009.

\section{PROMOVER O SABOR DOS SABERES NA ESCOLA}

Bernadette Feury (BF) - Teu último livro chama-se La saveur des savoirs, disciplines et le plaisir d'apprendre [O sabor dos saberes, as disciplinas e o sabor de aprender]. O que entendes por "promover o sabor dos saberes na escola"?

Jean-Pierre Astolfi (JP) - Inicialmente é necessário partir da etimologia e lembrar que "sabor" e "saber" são a mesma palavra: do latim sapere. Mas, isto se perde um pouco na escola porque os saberes para os alunos (e muitas vezes mesmo para os professores) são principalmente coisas trabalhosas, aborrecidas e obsoletas, para memorizar... E que estão longe de serem saborosas! O sabor muitas vezes desaparece quando o saber torna-se escolar.

Uma das maneiras frequentes de tentar sanar esta questão - eu não digo que ela seja sem interesse - é procurar substitutos para o saber. É procurar no campo das competências, no campo da interdisciplinaridade, no campo dos objetivos. Durante muito tempo, se disse que os saberes eram difíceis e sempre exigentes e que eles não comportavam em si mesmo o prazer de aprender. Então, era necessário, de uma maneira um pouco superficial, a partir do exterior, dar-lhes um pouco de vida. De acordo com uma fórmula que eu propus, a questão é saber se se trata de colocar flores no cemitério ou de ressuscitar os mortos! Muito frequentemente se coloca flores no cemitério para tentar embelezar os saberes aborrecidos, acadêmicos..., quando o problema é restituir aos saberes das disciplinas o seu fundamento. 
Ora, todo saber, no seu fundamento, trouxe prazer, alegria, conhecimento novo, um desabrochar, um "heureca", uma maneira nova de ver o mundo e as coisas! Cada disciplina é, assim, uma maneira original de ver o mundo. E os professores dos quais nós nos lembramos com alegria são justamente aqueles que souberam nos comunicar este novo sabor através dos conteúdos, dos capítulos, das perguntas, das tarefas... Com os outros, isto se resumia a uma sucessão de lições... O sabor dos saberes não é um artifício (uma maneira exterior e artificial de reembelezar as coisas). É voltar à origem daquilo que é um saber. Os saberes são ligados às disciplinas.

BF - Tu fazes, de fato, uma extraordinária apologia das disciplinas. Tu qualificas-as de "gigantes que nos carregam sobre seus ombros".

JP - Pois é! Disciplinas... Não se fala o suficiente... Em todo o caso, temos a tendência de considerá-las como reducionismos, como maneira tacanha de ver as coisas. Como se as disciplinas cortassem o mundo em fatias e impedissem de ver a globalidade das coisas, seu aspecto sistêmico... Existe toda uma literatura que tenta dizer: "Saiamos das disciplinas!" Existe, claro, coisas extremamente interessantes na interdisciplinaridade, mas com a condição de não negar as próprias disciplinas!

A primeira tendência do pensamento - da construção do pensamento - é a tendência disciplinar. Por trás, pode haver outras tendências sejam elas inter ou pluridisciplinares (porque o risco de reducionismo existe), mas a primeira tendência é a construção das disciplinas. Por quê? O que é, no fundo, uma disciplina? As disciplinas - e podemos considerá-las todas: disciplinas científicas, disciplinas literárias, disciplinas artísticas - são construções humanas que renovam consideravelmente a maneira segundo a qual, até determinado ponto, costumávamos ver as coisas. E é por esta razão que eu retomei esta velha expressão da Idade Média de Bernard de Chartres, do século XII, que diz: "Nós somos anões aninhados nos ombros de gigantes. Se nós vemos melhor e mais longe do que eles, não épela melhor qualidade de nossa visão, mas em função da sua altura gigantesca: ela é que renovou a nossa maneira de perceber e compreender as coisas."

E uma das primeiras coisas, uma das coisas fundamentais, eu creio, do nascimento e do desenvolvimento de cada disciplina, é a sua capacidade de dizer "não" a tudo que se acreditava até então, de dizer "não" ao senso comum. Geralmente se encara as disciplinas como conteúdo de conhecimentos, como conteúdos acadêmicos, memorizados, como série de teoremas, de regras (certamente existem coisas como estas). Mas, em princípio, uma disciplina é uma transformação do que se acreditava, pensava-se e se vislumbrava até então. É o que Bachelard chama de "filosofia do não" - N.O.N.! [não] Niet! Para brincar com as palavras, se pode dizer que aqueles que criaram as disciplinas e que deixaram seu N.O.M. [nome] são aqueles que disseram N.O.N. [não].

"O sol nasce, o sol se põe", durante séculos e milênios se disse: "Sim, claro, isto fala por si, é evidente...” Na Renascença, o início da Astrofísica foi a renún- 
cia a esta certeza. "Não!" Apesar de todas as aparências e do que se acreditava saber desde sempre, não é o sol que se levanta pela manhã e se põe à noite, mas, ao contrário, é a Terra que gira em torno do sol. Mas, isto demorou muito, foi muito difícil! Foi necessário quase um século de combate de Kepler à Galileu, passando por Tycho Brahe na Dinamarca e todos os seus inimigos, evidentemente... Foi um combate! Isto não foi aceito de saída e se sabe bem que o Vaticano ameaçava de excomunhão porque isto parecia contrariar a religião. Foi necessário tempo para (como se diz hoje em dia) trocar o paradigma. Para trocar o modelo de interpretação, de compreensão. Mas, o que eu disse para a Astronomia, é verdadeiro para a Física, verdadeiro para a Química... Para a Física é principalmente Newton; para a Química é, sobretudo Lavoisier; para a Biologia têm-se várias figuras como as de Mendel; para as Ciências Humanas, mais tarde, com Freud... A teoria freudiana sobre a sexualidade de crianças pequenas na cidade de Viena no fim do século XIX, o que foi senão uma filosofia do não, uma recusa da maneira segundo a qual se tinha encarado as coisas até então?

No início, existe como uma negação e então se criam novos conceitos. Isto cria novas formas de ver, de compreender, de interpretar, de analisar... Que terminam (se elas ganham) por se tornarem dominantes. E é então que um paradigma substitui um outro paradigma.

O que é dramático na escola é que esta dimensão dinâmica, esta dimensão de luta desaparece! E a gente acaba por pensar que foi sempre assim. Desde que o novo paradigma se instala, quando se fazem manuais, dicionários, enciclopédias, as maneiras anteriores de pensar parecem ser erradas, parecem falsas. Mas, era outra maneira de pensar que tinha seu interesse e seu valor, mas que esgotou seu propósito de interpretar o mundo e que então foi necessário renovar para ir mais longe.

Esquecemos, por exemplo, na Biologia, que a noção de célula exigiu uma luta muito longa... A palavra célula começou a ser utilizada no século XVII. As células vistas por Leeuwenhoek ${ }^{2}$ (um grande sábio holandês) eram exceções, coisas um pouco particulares, estruturas. Não eram a unidade, o tijolo unitário geral de todos os seres vivos. A palavra existia, mas não o conceito. Foram necessários, digamos, duzentos anos, para chegar a instalar, no século XIX, a ideia de célula como sendo a unidade de base anatômica e funcional do organismo. Até o inicio do século XX, no que se refere ao sistema nervoso, o debate continuava. É a construção disto que fez nascer a Biologia.

\section{OS CONCEITOS: FERRAMENTAS PARA O PENSAMENTO.}

BF - Portanto, poderíamos dizer, afinal, que quando tu lutas pela reintrodução do sabor dos saberes na escola, tu queres promover as disciplinas não como conteúdos quase mortos para memorizar, mas como um potencial de interpretação... 
JP - Sim, um potencial de nova interpretação, como uma maneira distinta de pensar as coisas!

Além disto - incluindo aí também os alunos em dificuldade escolar os momentos de escolaridade dos quais eles se lembram são os momentos de heureca: “Ah! mas é claro! Eu nunca tinha visto a coisa desta maneira!” E quando um professor nos faz ver o mundo, as coisas e a disciplina de outro modo que não aquele com o qual estávamos acostumados e que nos haviam sempre repetido, o saber torna-se uma alegria! Assim, o saber é uma ferramenta do pensamento. É uma ferramenta, não fórmulas para repetir ou definições para copiar! Existem definições, fórmulas, regras, teoremas, mas isto vem mais tarde e estes elementos só adquirem todo o seu sentido se nós chegamos a compreender a renovação do pensamento que foi necessário para chegar até eles.

BF - Então há, de fato, uma espécie de empobrecimento do saber escolar.

$$
\text { JP - Sim! }
$$

BF - Há uma frase, no teu livro, que é importante para nós na agricultura, pois nós fazemos frequentemente observações de paisagem. Tu dizes: "Frente a uma paisagem, quem não tem conceitos não vêe nada, mas aquele que os tem nem sabe que os possui."

$$
\mathrm{JP}-\operatorname{Sim} \ldots
$$

BF - De início, ele não pode nem mesmo desvelá-los...

JP - Sim, este é o paradoxo!

BF - Nós dizemos aos alunos, por exemplo: "Observem!”

JP - É isto: “Observem!”... A observação da paisagem... Mas se não se tem noções para apreender, não se vê nada! Claro que se pode escolher, pode-se fazer observações geográficas, econômicas, geológicas... Eu sou principalmente geólogo de formação. Eu me lembro de lugares na Córsega da minha infância, dos quais os geólogos diziam que não se conhecia nada, cada um tinha a sua teoria; e há lugares que eu fui, no tempo da faculdade, nos quais eu ficava frente a frente com a diversidade de interpretações não estabilizadas (porque a geologia da Córsega é verdadeiramente muito complicada). Foi necessário bastante tempo para que um paradigma emergisse (enquanto a tectônica de placas não existia não se compreendia nada). E hoje, nesses locais, que eu conheço há quarenta, cinquenta anos, levam-se os estudantes, de ônibus, para lhes mostrar as extrusões submarinas típicas: "Olhem, vocês raramente verão outras tão magníficas!" 
BF - Elas não tinham sido vistas antes?

JP - Então, vê-se com os olhos? Porque os geólogos dos quais falei eram bons conhecedores do terreno, trabalhavam no campo constantemente, mas eles não viam. E por que eles não viam? Porque eles não tinham os conceitos! Não era porque eles não tinham as qualidades de observação, é que eles não tinham os conceitos (a tectônica de placas). Eles não tinham o bom paradigma!

BF - Para a análise das práticas, tu dizes em algum lugar que "é a teoria que cria os observáveis".

JP - Mas é claro! É ela que cria os observáveis!

BF - Tu evocas Latour que diz "Não é a olho nu que se vê o mundo..."

JP - "É com o olho armado", sim. E armado com o que? Com teorias! É necessário que haja quadros de referência, conceitos. O paradoxo é que, de um lado, se não se tem os conceitos, não se vê nada ou somos atraídos por coisas superficiais (pela beleza da paisagem, pelos detalhes das rochas, dos fósseis ou das plantas que estão lá, mas que não são coisas essenciais aos olhos do especialista). De outro lado, frequentemente, aquele que se esforçou para adquirir os conceitos, esquece de sua anterior ingenuidade de espírito, esquece tudo que lhe custou para poder aceder ao novo estado e termina dizendo: "Vejam, isto está claro, observem...!" Ele incita os alunos a olhar, pois ele mesmo não sabe mais olhar de outra forma, senão com os olhos do especialista que se torna uma espécie de visão de segurança. Vê-se com o cérebro e não com a retina. É o cérebro que organiza a retina e não a retina que leva ao cérebro.

$$
\begin{aligned}
& \text { BF - E então... } \\
& \text { JP - ...de repente... }
\end{aligned}
$$

BF e JP - "Ele não compreende que os alunos..."

JP - É a mais célebre das frases de Bachelard, sem dúvida: “Os professores não compreendem que os alunos não compreendam”. Não tendo mais consciência das suas antigas ferramentas de interpretação, não tendo mais consciência do que lhe custou construir estes conceitos e se afastar do senso comum, os professores acabam por considerar as coisas como evidentes e se surpreendem que os alunos continuem a se enganar. 
BF - O saber escolar estaria sofrendo por não ser suficientemente teórico?

JP - Sim, é isto! Eu gosto de usar este paradoxo quando se diz com gosto que é necessário "tornar o saber mais concreto", que é necessário "dar exemplos"... É claro que é necessário tornar o saber concreto, que é necessário dar exemplos, mas cuidado, pois há um risco permanente de que o exemplo esconda o conceito!

Com os trabalhos de Britt-Marie Barth, por exemplo, já se havia mostrado, há alguns anos, que os alunos veem o exemplo. Mas o exemplo é um exemplo de que? É só perguntar aos alunos na saída de uma aula. Brincando, eu digo sempre aos professores: "Tratem de nunca estar lá quando os alunos que saem da aula dizem para aqueles que entram o que foi estudado hoje (risos). É algo para fazer você tomar tranquilizantes pelo resto de sua vida"... Os alunos não sabem dizer o que estudaram! Eles vão dizer sobre o que se falou, sobre o exemplo trabalhado, se havia um material específico, se havia microscópios, se foi visto um filme, se havia documentos... Mas qual era a noção que estava sendo ensinada? O conceito que estava sendo ensinado através daquela aula, qual era? A noção, o conceito... o que você diz sobre isto? É que para muitos alunos a aula não é suficientemente teórica. É porque, nos dias escolares, sucedem-se as disciplinas, onde os alunos fazem coisas, cada coisa seguinte apagando a anterior. $\mathrm{E}$ quando acaba os alunos não sabem o que fizeram... Por quê? Porque não se identificou a pepita conceitual que existe em uma lição dada pelo professor. Existe um jogo de questões e resposta perfeitamente adaptado. É o que Philippe Perrenoud chama de "profissão de aluno". Os alunos sabem perfeitamente exercer sua profissão: fazer as boas perguntas permite chegar às boas respostas esperadas, no tempo adequado. Mas, no entanto, os alunos constroem conceitos? Os alunos percebem o que é necessário aprender por trás disto? Alguns sim, mas a maioria, e principalmente os alunos com dificuldade, fica completamente à margem. Então, é necessário sim que o saber seja mais teórico; sim, principalmente para os alunos com dificuldade escolar!

BF - Isto vai ao encontro dos trabalhos da equipe ESCOL (Bautier, Charlot e Rochex, 1992) ${ }^{3} \ldots$

JP - Sim, isto se alinha de certa forma aos trabalhos da equipe ESCOL sobre a questão da relação com o saber.

BF - E, portanto, é importante para aqueles alunos que naturalmente não conceitualizam que os professores tenham como objetivo essencial equipá-los com os conceitos.

JP - É sim! E os alunos que não conceitualizam espontaneamente são a maioria. Mas, a equipe ESCOL é formada por sociólogos, eles falam de uma relação com o saber de uma maneira mais geral e independentemente das disci- 
plinas. E eu, o que eu digo aproxima-se mais da ideia de relação disciplinar com cada um dos saberes disciplinares.

\section{ACOMPANHAR O NECESSÁRIO PROCESSO DE CONCEITUAÇÃO}

BF - A propósito, na nossa rede pedagógica, na análise das práticas pedagógicas, nós utilizamos uma ferramenta muito reveladora que nós tomamos da tua obra L'école pour apprendre [Escola para aprender]: é o famoso "círculo de conceitualização”. Tu poderias comentá-lo? Explicá-lo novamente?

Figura 1 - 0 círculo da conceitualização.
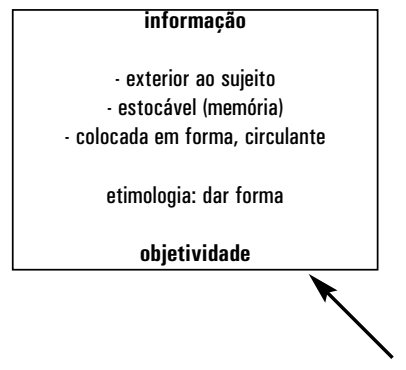

transformação do processo em um produto estabilizado, revisão contínua dos saberes

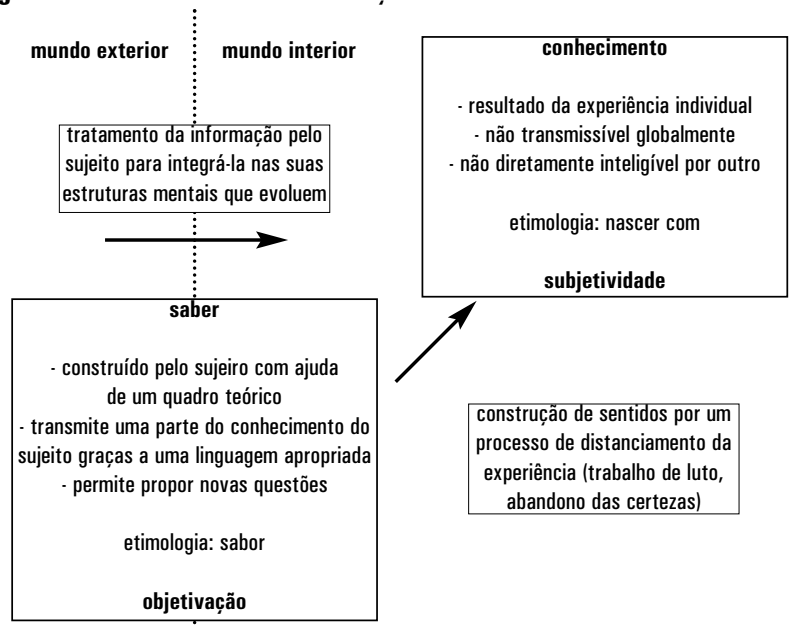

JP - Sim; se pode dizer que é um tríptico que engloba três palavras próximas que são empregadas geralmente como sinônimos: informação, conhecimento e saber. Ora, estas três palavras (e existem outras) eu também as utilizo tal como o senso comum, indiferentemente. A questão não é policiar o vocabulário. A questão é perceber os conceitos e as diferenças conceituais que podem estar por trás delas. Mas, se eu selecionei estas três palavras (apoiando-me também em outros autores - Legroux, Monteil), é porque sua etimologia é interessante: informação, conhecimento e saber. "Informação" vem do latim informare: colocar em determinada forma. E a disciplina, é isto que ela faz. Ela coloca o saber dentro de uma determinada forma.

Estamos atropelados pela informação; estamos imersos em um universo de informações. E frequentemente o professor acredita dar conceitos, noções, mas na realidade, o que faz é dar palavras as quais, para os alunos, ficam em um plano léxico e informativo. Uma grande quantidade de informações destiladas pela escola não chegam ao nível de conceito. 
BF - Existe, então, uma trajetória a acompanhar...

JP - Sim, há uma trajetória a acompanhar, porque além de tudo isto, os alunos já têm, em suas cabeças, conhecimentos próprios: certa forma de conhecimento que é a sua explicação do mundo (etimologia "connaissance": nascer com $)^{4}$. Os conhecimentos são sua representação do mundo. Desde a época da mamadeira as crianças têm ideias sobre a alimentação. Desde que jogam bola, desde que tomam banho, as crianças têm representações sobre lançar uma bola, sobre o que flutua e o que escorre, e estas noções são resistentes! Laurence Viennot, na Física, mostrou isto há muito tempo. $\mathrm{Na}$ escola fundamental, na Educação Infantil, mas também no Ensino Médio se vê (apesar de tudo que lhes é ensinado, apesar das horas e horas do aprendizado das disciplinas), a manutenção das representações intocadas. André Giordan trabalhou muito sobre estas questões. Ele fez demonstrações. Todos pode refazê-las quando quiserem, com seus próprios alunos, e chegarão às mesmas constatações. Estas representações filtram a informação.

BF - É o que se encontra, ao final, nos trabalhos dos alunos...

JP - Sim; encontram-se alguns elementos de informações dadas pelos professores, mas que são recolocadas no molde das representações inalteradas. $\mathrm{E}$, assim, existe muito pouca aprendizagem de conceitos.

BF - Existe outra etapa, então...

JP - Então existe a terceira etapa, que é justamente o trabalho de formação de conceitos. O círculo de conceitualização consiste em ultrapassar as informações tomadas como coisas a aprender, como simples objetos a memorizar, para transformar as concepções iniciais, as representações dos alunos (que são no fundo sua maneira de representar o mundo desde criança) em saber (etimologia sapere: sabor). A escola deve ser o local onde haverá uma transformação das representações que permitirão às informações dadas significarem outra coisa que não palavras, transformarem-se em instrumentos intelectuais, em novas ferramentas para o pensamento, tornarem-se conceitos! As coisas que se veem quando se sobe nos ombros de gigantes (para retomar a imagem).

BF - Pode-se dizer que o erro é uma ferramenta para ensinar?

JP - Sim... O erro é uma ferramenta para ensinar porque ele está no coração (e aí se volta a Bachelard) do processo de transformação intelectual, da renúncia custosa e difícil - causa, às vezes, até de ansiedade para alguns alunos porque é necessário abandonar o que já se sabe (explicações simples nas quais se 
acreditava e que funcionavam bem). E é necessário substituí-las por explicações muito mais complicadas que não se compreende facilmente. Então, não é nada, nada simples! E o erro tende a persistir, a retornar... E a aprendizagem (diz Bachelard), é um tecido de erros corrigidos, reformulados, que puderam ser retomados e retrabalhados.

Como professor, deveríamos ter paixão pelos erros dos alunos. E mesmo, de vez em quando, provocar os erros (alguns fizeram isto em pesquisas de didática das Ciências). E com armadilhas que induzem ao erro! Que fazem os alunos cair no erro, se ouso dizer! E que fazem os alunos reagir como cientistas do passado que cometeram erros. Os alunos poderão dizer: "Então, este erro, não é uma besteira minha! É um erro do qual se tem traços na história da Ciência." E todos os que saem na chuva se molham! O trabalho sobre o erro é um trabalho fundamental, essencial mesmo para se chegar aos conceitos. Os conceitos não são coisas, mas mudança de paradigma. Já se disse, mudanças na interpretação do mundo... Assim, evidentemente, é algo mais exigente, se pode dizer, também, que é mais elitista. É uma crítica que me fizeram algumas vezes. Este risco existe, é necessário não subestimá-lo, porque não são poucos os alunos que não pedem tanto e que já estão satisfeitos (como não poucos professores também) se as horas passaram sem maiores problemas, se os professores puderam chegar ao final da aula sem que os alunos fizessem bagunça, se os alunos chegaram ao fim da aula sem terem tido que ir ao quadro... Nossa! Todo mundo fica contente! Volta-se à questão da "profissão de aluno" da qual falávamos há pouco.

Mas, o que se esquece, afinal, é a questão: o que é, de verdade, um saber. E para muitos alunos, é necessário dizê-lo, que é somente quando chegam à universidade - porque lá eles entram no mundo do saber sábio e seus contextos (com as escolas de pensamento, diferentes especialistas) que, de repente, os alunos veem o que é a sua própria disciplina. Mas nem todos vão à universidade! E todos os que pararam no nível do diploma técnico ou do Ensino Médio arriscam-se (sobretudo se suas famílias não têm condições de custear uma volta aos estudos) de nunca ter experimentado esta descoberta, esta alegria do saber, do sabor dos saberes!

BF - Mas para os professores, o grande problema, é estarem eles mesmos conscientes dos conceitos que é necessário ensinarem. Damo-nos conta de que as orientações curriculares são escritas de modo que não se acha facilmente os conceitos. Existem mesmo um certo número [de conceitos] essenciais que não são jamais explicitados. Tanto que, parte de nossa atividade de ensino e da atividade de aprendizagem dos alunos passa ao lado do alvo, porque de fato não o miramos.

JP - Pois é: nós não o miramos! Frequentemente não é falta de boa vontade! É difícil! Portanto, eu não acuso ninguém! 
BF - É necessário trabalhar em grupo para...

JP - ...Sim, é necessário trabalhar em grupo, refletir coletivamente em estágios, em formações coletivas... Porque efetivamente este trabalho está longe de ser simples! Já aconteceu, em cursos de formação em didática das Ciências que eu frequentemente organizei, de abordar um capítulo de um livro didático e pedir aos professores para identificar três ou quatro conceitos que estão no âmago daquela lição. Tal orientação desencadeia um tipo de guerra inacreditável entre os professores, que talvez estejam de acordo sobre o que será necessário solicitar aos alunos para copiar em seus cadernos, mas que estão longe de estar de acordo sobre o essencial das lições que estão ali. Eles dizem: "Ah, não! Eu nunca vi isto desta forma..." Veem-se às vezes disputas - e daí tomadas de consciência salutares - porque talvez mesmo em nossa formação de base universitária, nós tivemos poucas ocasiões de estar engalfinhados com o saber vivo, com o saber renovador que transforma nossas representações. Claro que nós sabemos coisas que se pode repetir; que se pode retomar; que não são inúteis, que servem para fazer exercícios, para passar para anos seguintes, para passar nos exames... Mas, quando nós interrogarmos estudantes bem sucedidos no Ensino Médio e que estão às portas dos institutos de formação de professores, nos admiramos em constatar a manutenção intocada das representações em Física, em Biologia, etc.

\section{OS PROFESSORES E A REVOLUC̣ÃO CONSTRUTIVISTA}

BF - Mas então, para se aceder justamente a estes conceitos, para chegar a identificá-los e colocá-los como objetivos, não é preciso que nós professores façamos - eu vou recorrer ao jargão detestado pelos anti-pedagogia - não é necessário fazer a sua "revolução construtivista"?

JP - Pois é; é isto! É necessário fazer a sua revolução construtivista... É só no francês que esta expressão é um palavrão (até um insulto). Eu circulei bastante por diversos países, e o que se vê é que por todo lugar, na formação dos professores, mesmo nos confins da América Latina... Todos os professores sabem a diferença, em espanhol, por exemplo, entre "conductismo" e "constructivismo". É só na França que ninguém ouviu falar disto! Ou então muito poucos...

Qual é a diferença? "Conductismo" é o que nós chamamos de behaviorismo, é a ideia de que se aprende por cópia fiel, repetindo as coisas que já foram vistas (ingurgitando-as e regurgitando-as). E o construtivismo? Ele é triplo, de certo modo. Eu não sei como dizer... Tenho medo que seja muito complexo... É necessário ser construtivista em três niveis:

(1) Construtivista, "uma vez" (como dizem na Bélgica), de um ponto de vista psicológico (C1): porque é aquele que aprende que constrói o conhecimento e 
ninguém pode fazê-lo em seu lugar. E é sempre um erro e uma ilusão pensar na transmissão de conhecimentos. Os conhecimentos não se "transmitem" eles se reconstroem! E assim, entre todos os psicólogos, de Piaget à Bruner, passando por Vygotski (e Deus sabe que não há acordo de todos sobre as teorias psicológicas), nenhum deles é behaviorista! Todos dirão: "Existe uma ação ativa do sujeito que aprende e é ele que deve fazer este processo". A partir do fim do behaviorismo em psicologia (digamos, na década de 1950) é na atividade mental do sujeito que acontecem as coisas. Assim, isto é ser construtivista uma vez: é o sujeito que constrói e reconstrói o saber. Evidentemente não a partir do nada, mas a partir de atividades que lhe serão sugeridas (mas isto será o terceiro: C3).

(2) Existe um segundo construtivismo que eu já evoquei: é um construtivismo, sobretudo epistemológico (C2) que enfatiza o caráter construído das disciplinas. Cada disciplina é uma construção afastada do senso comum; uma construção difícil que levou ao abandono das representações para entrar em um outro sistema de interpretação. Assim, o objeto do saber é construído (C2) e o sujeito deve por si, reconstruí-lo ativamente (C1).

BF - Portanto, isto introduz um terceiro construtivismo...

JP - O terceiro é pedagógico (C3): são necessários dispositivos construtivistas. Porque o construtivismo não vai acontecer por si só. É necessário que o professor, ou o formador, crie dispositivos que permitirão acontecer coisas que não aconteceriam se eles não estivessem lá.

Frequentemente se houve falar: "Não se deve ser diretivo, é necessário que os alunos encontrem por eles mesmos!" Evidentemente, eu não tenho nada contra, mas ao mesmo tempo eu penso: "Como os alunos vão descobrir por si próprios o que justamente eles ignoram? Como eles vão descobrir por eles mesmos o que foi tão difícil e demorado na história das disciplinas? Poderão eles encontrar isto, em uma hora, em um golpe de varinha mágica...?” Não é possível!

Existe, então, uma grande necessidade de construir (a didática ainda tem um longo caminho a sua frente) dispositivos didáticos construtivistas que levarão os alunos e professores a trilhar o caminho do trabalho com obstáculos e transformações do erro para, modestamente (como se pode e sem que haja milagres), chegar a conhecimentos de um novo tipo.

E aí, existe uma felicidade, um prazer que George Snyders (que foi professor de Educação na Sorbonne) descreveu há muito tempo. Ele falou da alegria na escola e eu creio que ele foi incompreendido neste ponto durante muito tempo, porque isto aconteceu na época da "não-diretividade" (anos 1968). Naquela época, pensava-se que os alunos iam descobrir tudo por eles mesmos, na sua liberdade. Alguns alunos talvez possam, mas é necessário construir dispositivos.

Então, construtivismo uma vez, de um ponto de vista psicológico, porque é o aluno que constrói o seu saber; construtivismo duas vezes, porque a disciplina e 
cada uma das disciplinas são uma construção difícil, para além do senso comum; e construtivismo três vežes, porque é necessário construir dispositivos que conduzam os sujeitos neste esforço permanente que é, no fim das contas, produtor da felicidade do saber e do prazer de apreender através das disciplinas.

Quadro 1 - 0s três construtivismos.

\begin{tabular}{|c|c|c|}
\hline $\begin{array}{l}\text { CONSTRUTIVISMO EPISTEMOLÓGICO } \\
\text { (C2) }\end{array}$ & $\begin{array}{l}\text { CONSTRUTIVISMO PSICOLÓGICO } \\
\text { (C1) }\end{array}$ & $\begin{array}{l}\text { CONSTRUTIVISMO PEDAGÓGICO } \\
\text { (C3) }\end{array}$ \\
\hline $\begin{array}{c}\text { Os saberes não são coisas que se } \\
\text { amontoam. }\end{array}$ & 0 aluno não é uma página em branco. & 0 ensino não se faz por simples transmissão. \\
\hline $\begin{array}{l}\text { Os conteúdos não enumeram fatos, mas } \\
\text { propõem respostas a problemas teóricos. }\end{array}$ & $\begin{array}{l}\text { A aprendizagem não se dá por cópia, por adj- } \\
\text { ção, nem por adestramento, mas requer ativi- } \\
\text { dade autônoma do sujeito. }\end{array}$ & $\begin{array}{c}0 \text { ensino não projeta ou passa o filme do } \\
\text { conhecimento perante } 0 \text { aluno, mas exige } \\
\text { dispositivos didáticos. }\end{array}$ \\
\hline $\begin{array}{l}\text { Os saberes resultam de um esforço de } \\
\text { construção epistêmica social e cultural. }\end{array}$ & $\begin{array}{l}\text { Aprender necessita uma construção ativa por } \\
\text { parte do sujeito dentro de um contexto social. }\end{array}$ & $\begin{array}{l}\text { Ensinar exige uma engenharia didática coe- } \\
\text { rente com os objetivos visados e com os } \\
\text { obstáculos a ultrapassar. }\end{array}$ \\
\hline Aqui é o saber que é construído. & Aqui é 0 aluno que deve construir 0 seu saber. & $\begin{array}{l}\text { Aqui é o professor que deve construir as } \\
\text { situações. }\end{array}$ \\
\hline Antônimos: empirismo e positivismo & Antônimos: empirismo e positivismo & Antônimo: dogmatismo \\
\hline
\end{tabular}

Fonte: J.P. Astolfi. La saveur de savoirs, [Paris:] ESF, 2008.

BF - Estamos a tal ponto impregnados pelo behaviorismo - especialmente no ensino agrícola, depois de uma quinzena de anos de intensiva pedagogia por objetivos - que é difícil mudar de modelo. Existem tantas resistências...

JP - Foi Philippe Perrenoud quem escreveu um magnífico artigo que intitulou "Você é a favor ou contra a gravitação universal?"5 e ele diz: "Imagine um debate entre físicos onde a questão que lhes é colocada seja: "Você é a favor ou contra a gravitação universal?” Os físicos debatem entre si, pertencem a escolas de pensamento diferentes, têm congressos, têm periódicos concorrentes, concorrem pelos postos profissionais, etc., mas são todos a favor da gravitação universal porque é o paradigma mais aceito, mais bem demonstrado, o que explica melhor as coisas, e nunca mais se vai retornar ao século XVII e ainda menos à Idade Media!

Mas em Educação se pode! Se pode sempre negar e se pode dizer: "Eu sou a favor da transmissão. Eu sou um partidário da transmissão dos saberes!" Mas a transmissão dos saberes não existe. Porém, cuidado: aqui também é preciso ser prudente e não ser muito esquemático. Existe, de fato, uma transmissão, mas é uma transmissão social, entre gerações. Nós estamos na escola para transmitir às novas gerações conceitos de Física, de Química, de História, de Geografia, de filosofia... De todas as disciplinas. Assim, existe mesmo uma ideia de transmissão. Mas esta transmissão entre gerações não passa por um mecanismo individual de transmissão, pela repetição mecânica das coisas. É cada aluno que deve percorrer o caminho de reconstruir, de reconquistar, para que no final das contas aquela geração adquira, por seu lado, este conhecimento e acabe por esquecer que ela o adquiriu. Volta-se sempre ao mesmo ponto... Para que isto se torne uma maneira de pensar quase automática... 
BF - Para ti, não ser construtivista no campo da Educação é como recusar a gravitação universal?

JP - É um pouco como recusar a gravitação universal para um físico!

Mas, evidentemente, a Educação está sempre ligada a debates que são perfeitamente legítimos e compreensíveis! Porém, a cada início de ano letivo, sabemos que surge uma literatura antipedagógica que contribui para confortar professores, pais, políticos através de suas representações e suas concepções sobre o que é a aprendizagem. E aí também existem concepções resistentes sobre o ato de aprender que é confundido com o ato de ensinar.

\section{A ANÁLISE DAS PRÁTICAS PEDAGÓGICAS}

BF - E para terminar, posso pedir-te apenas alguns conselhos sobre a análise das praticas pedagógicas?

JP - Eu não gosto muito de dar conselhos...

BF - Pontos cruciais que te parecem importantes?

JP - Eu tenho consciência que é difícil e, mais uma vez, em tudo que eu disse, não há critica a ninguém e não há nenhuma desconfiança com relação aos professores, individual e coletivamente... Porque é difícil e porque se é constantemente confrontado a obstáculos epistemológicos sobre as concepções de aprendizagem. Para responder a tua questão, eu já constatei: é comum, mesmo com os professores que estão convencidos, que pertencem a movimentos pedagógicos..., muito frequentemente ao fazer análise das práticas, o saber desaparece. Significa que durante a análise, não se vê com os olhos (dissemos isto anteriormente), vê-se através de conceitos, com categorias mentais que estão integradas em nós. Mas, o observador do fundo da classe vê frequentemente com os olhos do ensino tradicional; ele está essencialmente atento às interações, à participação: será que todos os alunos estão ativos? Todos os alunos falam? Existe diálogo? O observador vê o que aparece: houve atividade intelectual, material? Houve produção dos alunos? etc. Tudo isto está muito bem, mas pode existir tudo isto sem que o saber esteja no centro da atividade escolar! E aí, concordamos novamente com a equipe ESCOL para dizer: "a relação com o saber está longe de ser simples; ela necessita ser retrabalhada" para que os alunos se deem conta que não existe somente saberes a adquirir, mas também uma relação com o saber, e com cada um dos saberes disciplinares, a desenvolver e a trabalhar. E é por isto que a escola é difícil. 
BF - Para terminar, eu gostaria apenas de tranquilizar-te quando dizias que não querias parecer estar fazendo criticas aos professores...

$$
\text { JP - Pois é... sim... }
$$

BF - Eu gostaria de dizer-te que em nosso percurso pedagógico, os teus livros não nos pareceram nunca como críticas, mas, sobretudo como companheiros no difícil caminho de nossa revolução construtivista...

$$
\begin{aligned}
& \text { JP - Que bom, eu fico contente. } \\
& \text { BF - Obrigada. } \\
& \text { JP - Obrigado. }
\end{aligned}
$$

\section{NOTAS}

${ }^{1}$ Centre Interdisciplinaire sur les Valeurs, les Idées, les Identités et les Compétences en Education et en Formation, Universidade de Rouen (nota da tradutora)

2 NT: No texto original o nome grafado é "Leveno", mas penso tratar-se de imprecisão da transcrição da entrevista oral.

3 NT: Sem referência no original. Presumo tratar-se da obra École et savoir dans les banlieues et ailleurs de Bernard Charlot, Élisabeth Bautier et Yves Rochex. Paris : Armand Colin, 1992.

${ }^{4}$ NT: no original "connaissance: naitre avec"

$\mathbf{5}$ NT: texto disponível em:

http://www.unige.ch/fapse/SSE/teachers/perrenoud/php_main/php_2003/2003_22.html. Tradução autorizada. 